\title{
The prognostic impact of GSTM1/GSTP1 genetic variants in bladder Cancer
}

\author{
Nada Albarakati ${ }^{1}$, Dareen Khayyat ${ }^{2}$, Asharf Dallol ${ }^{3}$, Jaudah Al-Maghrabi ${ }^{4,5}$ and Taoufik Nedjadi ${ }^{* *}$
}

\begin{abstract}
Background: The glutathione S-transferases (GSTs) are a superfamily of phase II detoxifying enzymes that inactivates a wide variety of potential carcinogens through glutathione conjugation. Polymorphic changes in the GST genes have been reported to be associated with increased susceptibility to cancer development and anticancer drug resistance. In this study, we investigated the association between genetic variants in GSTM1 and GSTP1 and patients' clinicopathological parameters. The prognostic values of such associations were evaluated among bladder cancer patients.

Methods: Genotyping of GSTM1 and GSTP1 in bladder cancer patients was assessed using polymerase chain reaction followed by DNA sequencing. Overall survival was estimated using the Kaplan-Meier method and multiple logistic regression and correlation analysis were performed.

Results: The GSTM1 null genotype was significantly associated with poor overall survival compared with the wild-type GSTM1 genotype. There was a trend towards better overall survival in patients with wild-type GSTP1 allele (AA) compared with GSTP1 (AG/GG) genotype. Interestingly, Kaplan-meier survival curve for GSTM1 null patients adjusted for sub-cohort with amplified HER2 gene showed poor survival compared with the GSTM1 null/ non-amplified HER2 gene. Also the same population when adjusted with HER2 protein expression, data showed poor survival for patients harboring GSTM1 null/high HER2 protein expression compared with low protein expression.
\end{abstract}

Conclusion: This study focuses on the impact of GSTM1 null genotype on bladder cancer patients' outcome. Further investigations are required to delineate the underlying mechanisms of combined GSTM ${ }^{--}$and HER2 status in bladder cancer.

Keywords: Bladder cancer, GSTM1, GSTP1, HER2, Polymorphism, Prognosis

\section{Background}

Bladder cancer is the 9th most common cancer and a leading cause of cancer-related death worldwide. It has been estimated that around 550,000 new bladder cancer cases and 199,922 deaths occurred in the year 2018 worldwide and these numbers are expected to double in the upcoming years [1]. The disease is highly recurring and do frequently progress to a muscle invasive phenotype which necessitate a vigilant and continuous monitoring protocol [2]. Despite advances in diagnostic and treatment modalities, bladder cancer remains source of co-morbidity and continues to pose challenges for clinicians given that

\footnotetext{
* Correspondence: nedjadita@ngha.med.sa

${ }^{1}$ King Abdullah International Medical Research Center, King Saud bin

Abdulaziz University for Health Sciences, Ministry of the National Guard -

Health Affairs, Jeddah, Kingdom of Saudi Arabia

Full list of author information is available at the end of the article
}

patients' outcome being solely dependent on the grading and staging system [3]. Therefore, a deeper understanding of the bladder cancer pathogenesis and associated mechanisms will undoubtedly improve patients' outcome via prevention of disease progression and recurrence.

It is well documented that occupational exposure to chemical carcinogens including aromatic amines and polycyclic aromatic hydrocarbons is associated with the risk of bladder cancer development [2, 4]. Kellen et al. reported an increased risk of developing bladder cancer associated with cumulative exposure to aromatic amines, but not to PAHs and diesel [5]. In an independent study, Ferrís et al. concluded that bladder cancer is a result of the interaction between constitutional and environmental risk factors including aromatic amines and polycyclic aromatic

(C) The Author(s). 2019 Open Access This article is distributed under the terms of the Creative Commons Attribution 4.0 International License (http://creativecommons.org/licenses/by/4.0/), which permits unrestricted use, distribution, and 
hydrocarbons [6]. The involvement of environmental factors such as cigarette smoking in bladder carcinogenesis has been extensively investigated [7, 8]. Recent evidence supports the dynamic interplay between environmental factors and other co-factors, including genetic predisposition, in the pathogenesis of bladder cancer [9].

Protecting against carcinogen-induced and chemotherapyinduced oxidative stress involves a series of event characterized by the activation of phase-II cellular detoxifying enzymes; Glutathione S-transferases (GSTs) or Nacetyltransferases (NATs) [10]. GSTs enzymes superfamily consist of at least 16 genes located on more than 7 chromosomes [11]. Although they are structurally different with distinct evolutionary origins, all GSTs isoenzymes are functionally similar in protection against electrophiles and oxidative stressors. The cytosolic sub-family of GST is found to be active in a homo- or heterodimeric state and is subdivided into eight classes designated as follow: GST alpha $(\alpha)$, mu $(\mu)$, kappa $(\kappa)$, omega $(\omega)$, pi $(\pi)$, sigma $(\sigma)$, theta $(\theta)$,

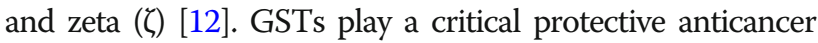
role through glutathione conjugation with a range of potentially cytotoxic exogenous or endogenous molecules making them less toxic. Allelic polymorphisms in these genes elicit changes in enzyme activities leading to biotransformation and play important role in the development and progression of different cancers, such as lung, colorectal, leukemia, breast and bladder cancers. Furthermore, Sau et al. showed the contribution of GSTs overexpression in resistance against several anti-cancer drugs [13].

GSTM1 gene is located on chromosome 1p13.3 and the most common polymorphic variant of GSTM1 gene is the homozygous deletion (GSTM1 null genotype) characterized by abolished enzyme activity [14]. Many studies have investigated the relationship between the genetic polymorphism of GSTM1 and the risk of cancer, but the association remains controversial among different populations. Previous epidemiological studies showed an association between the homozygous deletion of GSTM1 and increased risk of lung, colorectal and head and neck cancers [15-17]. However other studies failed to establish the association between GSTM1 null and the risk of several types of cancers [18-21].

GSTP1 is encoded by a single gene located on chromosome 11 [22]. The common functional GSTP1 polymorphism at codon 105 is an A to G substitution resulting in an amino acid switch from isoleucine to valine $\left(\mathrm{Ile}_{105} \mathrm{Val}\right)$ and lowering the catalytic activity of GSTP1enzyme [23]. The decreased detoxification capacity of the GSTP1 enzyme resulted in differences in chemotherapeutic responses. The increased expression of the GSTP1 Val105 genotype was shown to be associated with a variety of tumors, such as ovarian, breast, colon, lymphoma, and pancreas [24]. The hypothesis that GSTP1 variants modulate the risk of urinary bladder cancer has also been investigated [24, 25]. However, inconclusive results have been reported on the association between GSTP1 gene polymorphisms and the risk of bladder cancer: while a number of studies identified an obvious association between GSTP1 polymorphisms $\mathrm{Ile}_{105} \mathrm{Val}$ and bladder carcinoma risk [26-28], other studies illustrated that there are no association between GSTP1 $\mathrm{Ile}_{105} \mathrm{Val}$ polymorphism and bladder cancer $[29,30]$.

HER2 is a trans-membrane glycoprotein receptor tyrosine kinase of the epidermal growth factor receptor family EGFR/ErbB. It plays an important role in the development and progression of many tumor types including breast, gastric and bladder cancers [31]. Recent sequencing efforts to uncover the complex genomic landscape of bladder cancer identified six distinct molecular subtypes. HER2-like is one of the main subtypes characterise by higher ERBB2 amplification and signalling [32]. HER2 is considered one of the most important prognostic biomarkers that play an important role in the patho-physiology of bladder cancers and a potential therapeutic target in bladder cancer [31, 33, 34]. Also, interactions between GST gene family and other genes including HER2 may be involved in cancer susceptibility and clinical management of cancer patients. In the present study, we aim to investigate the prognostic value of GSTM1 and GSTP1 genetic polymorphisms in patients with bladder cancer and evaluate their association with patients' clinicopathological parameters. We also attempted to evaluate the clinical significance of HER2 status in cases confirmed to have GSTM1/ GSTP1 variants with bladder cancer prognosis.

\section{Methods \\ Patients and sample collection}

Formalin-fixed paraffin-embedded (FFPE) tissue samples were obtained from histologically confirmed bladder cancer patients who underwent bladder resection between 2005 and 2012 at King Abdulaziz University Hospital (KAUH), Jeddah, Saudi Arabia. The study group consists of 93 patients; only specimens containing more than $80 \%$ cellular composition were used in the analysis. All patients have not been subjected to any chemotherapy or radiotherapy prior to sample collection. Clinical and pathological data including age, gender, tumor grade, tumor stage, lymph node, vascular invasion, metastasis, and survival were gathered from patients' medical records and summarized in Table 1. This study was ethically approved by the institutional research ethics committee, faculty of medicine, King Abdulaziz University (ref. N. 149-14). 
Table 1 The clinicopathological characteristics of 93 patients with bladder cancer

\begin{tabular}{|c|c|c|c|}
\hline \multicolumn{2}{|c|}{ The clinicopathological characteristics } & \multirow{2}{*}{$\frac{N}{37}$} & \multirow{2}{*}{$\frac{\%}{39.78 \%}$} \\
\hline Group age (Years) & $\leq 60$ & & \\
\hline & $>60$ & 55 & $59.14 \%$ \\
\hline & Unknown & 1 & $1.08 \%$ \\
\hline \multirow[t]{2}{*}{ Gender } & Male & 77 & $82.80 \%$ \\
\hline & Female & 16 & $17.20 \%$ \\
\hline \multirow[t]{3}{*}{ Tumor Grade } & High Grade & 56 & $60.22 \%$ \\
\hline & Low Grade & 29 & $31.18 \%$ \\
\hline & Unknown & 8 & $8.60 \%$ \\
\hline \multirow[t]{3}{*}{ Cancer type } & MIBC & 52 & $55.91 \%$ \\
\hline & NMIBC & 28 & $30.11 \%$ \\
\hline & Unknown & 13 & $13.98 \%$ \\
\hline \multirow[t]{4}{*}{ Subtypes } & Transitional & 74 & $79.57 \%$ \\
\hline & Squamous & 3 & $3.23 \%$ \\
\hline & Transitional/ Squamous & 15 & $16.13 \%$ \\
\hline & Unknown & 1 & $1.08 \%$ \\
\hline \multirow[t]{3}{*}{ Tumor Shape } & Papillary & 63 & $67.74 \%$ \\
\hline & Non-papillary & 3 & $3.23 \%$ \\
\hline & Unknown & 27 & $29.03 \%$ \\
\hline \multirow[t]{3}{*}{ Lymph Node } & Positive & 21 & $22.58 \%$ \\
\hline & Negative & 68 & $73.12 \%$ \\
\hline & Unknown & 4 & $4.30 \%$ \\
\hline \multirow[t]{3}{*}{ Vascular Invasion } & Positive & 18 & $19.35 \%$ \\
\hline & Negative & 70 & $75.27 \%$ \\
\hline & Unknown & 5 & $5.38 \%$ \\
\hline \multirow[t]{3}{*}{ Metastasis } & Positive & 21 & $22.58 \%$ \\
\hline & Negative & 67 & $72.04 \%$ \\
\hline & Unknown & 5 & $5.38 \%$ \\
\hline \multirow[t]{3}{*}{ Smoking } & No & 11 & $11.83 \%$ \\
\hline & Yes & 16 & $17.20 \%$ \\
\hline & Unknown & 66 & $70.97 \%$ \\
\hline \multirow[t]{3}{*}{ Family history of cancer } & No & 24 & $25.81 \%$ \\
\hline & Yes & 4 & $4.30 \%$ \\
\hline & Unknown & 65 & $69.89 \%$ \\
\hline \multirow[t]{2}{*}{ Survival } & Alive & 65 & $69.89 \%$ \\
\hline & Deceased & 28 & $30.11 \%$ \\
\hline
\end{tabular}

Abbreviation: MIBC Muscle Invasive Bladder Cancer, NMIBC Non-Muscle Invasive Bladder Cancer

\section{DNA isolation}

Genomic DNA was extracted from FFPE tissue samples using QIAamp DNA FFPE Tissue Kit (Qiagen) according to the manufacturer's instructions. Purified DNA was eluted in $50 \mu \mathrm{l}$ elution buffer and stored at $-80^{\circ} \mathrm{C}$ until use. Purity and concentration of eluted DNA was analyzed using a spectrophotometer system (Nanodrop 2000, Thermo Scientific, USA).

\section{GSTM1 and GSTP1 SNP genotyping}

Genotyping for the detection of GSTM1 (present/null) and GSTP1 $\mathrm{Ile}_{105} \mathrm{Val}$ polymorphisms was performed as described previously [35]. Genotyping was carried out using real time PCR Kit (Qiagen) as per the manufacturer's recommendation. Briefly $200 \mathrm{ng}$ DNA was amplified in an overall volume of $25 \mu \mathrm{l} /$ reaction. GSTM1 and GSTP1 oligonucleotide primers were purchased from MWGBiotech (Ebersberg, Germany) to amplify the GSTM1 fragments, (Forward: 5'-CTGCCCTACTTGATTGATGGG3'; Reverse: 5'-CTGGATTGTAGCAGATCATGC-3'), GSTP1 (Forward: 5'-ACCCCAGGGCTCTATGGGAA-3', Reverse: 5'-TGAGGGCACAAGAAGCCCCT-3') PCR was performed on a Thermal Cycler 480 apparatus (Applied Biosystems, USA). Thermo cycler parameters included: an initial denaturation at $94{ }^{\circ} \mathrm{C} / 15 \mathrm{~min}$; followed by 35 cycles of denaturation at $94^{\circ} \mathrm{C} / 1 \mathrm{~min}$, annealing at $57^{\circ} \mathrm{C} / 1 \mathrm{~min}$, and extension at $74^{\circ} \mathrm{C} / 1 \mathrm{~min}$; and a final extension at $72{ }^{\circ} \mathrm{C} / 10 \mathrm{~min}$. Confirmation of PCR products were examined by $2 \%$ agarose gel electrophoresis and visualized using a Syngene UV transilluminator.

\section{DNA sequencing}

To sequence the amplified GSTP1 PCR products, sequencing kit (BigDye ${ }^{\circ}$ Terminator v3.1 kit, Thermo Scientific, USA) was used according to the manufacturer's instructions using Genetic analyzer 3500 (Applied Biosystems, UK). The resulting sequence data was analyzed using Applied Biosystems sequence analysis software (v 5.4). GSTP1 genotypes were determined as wild type Ile/ Ile (AA), heterozygous type Ile/Val (AG) or homozygous variant type $\mathrm{Val} / \mathrm{Val}$ (GG) as shown in Fig. 1c. As for GSTM1, the PCR products were separated on a $2 \%$ agarose gel and determined as null/ present genotypes.

\section{Immunohistochemistry}

HER2 immunostaining was undertaken earlier [33]. The expression of HER 2 protein is mainly membranous, the protein expression in our bladder samples was evaluated as follows: No expression $=$ negative Vs. Expression $=$ weak, +1 ; moderate, +2 ; strong, +3 .

\section{Statistical analyses}

Statistical data analysis was performed using SPSS (SPSS, version 25, USA). Appropriate, Chi-square test and Fisher's exact test were used to establish any significant differences in polymorphism incidences between bladder cancer cases. Multivariate Cox regression model were used to evaluate the prognostic significance of GSTs genes, HER2 and other clinicopathological factors. Cumulative survival probabilities were estimated using the Kaplan-Meier method, with log- 


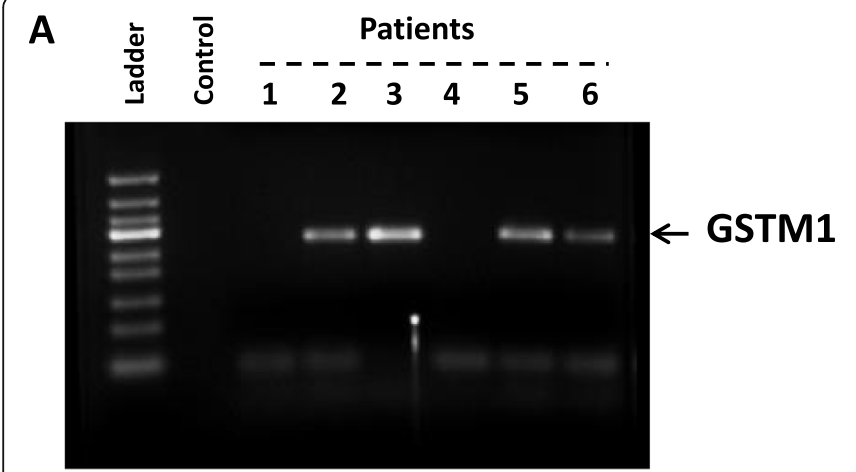

B
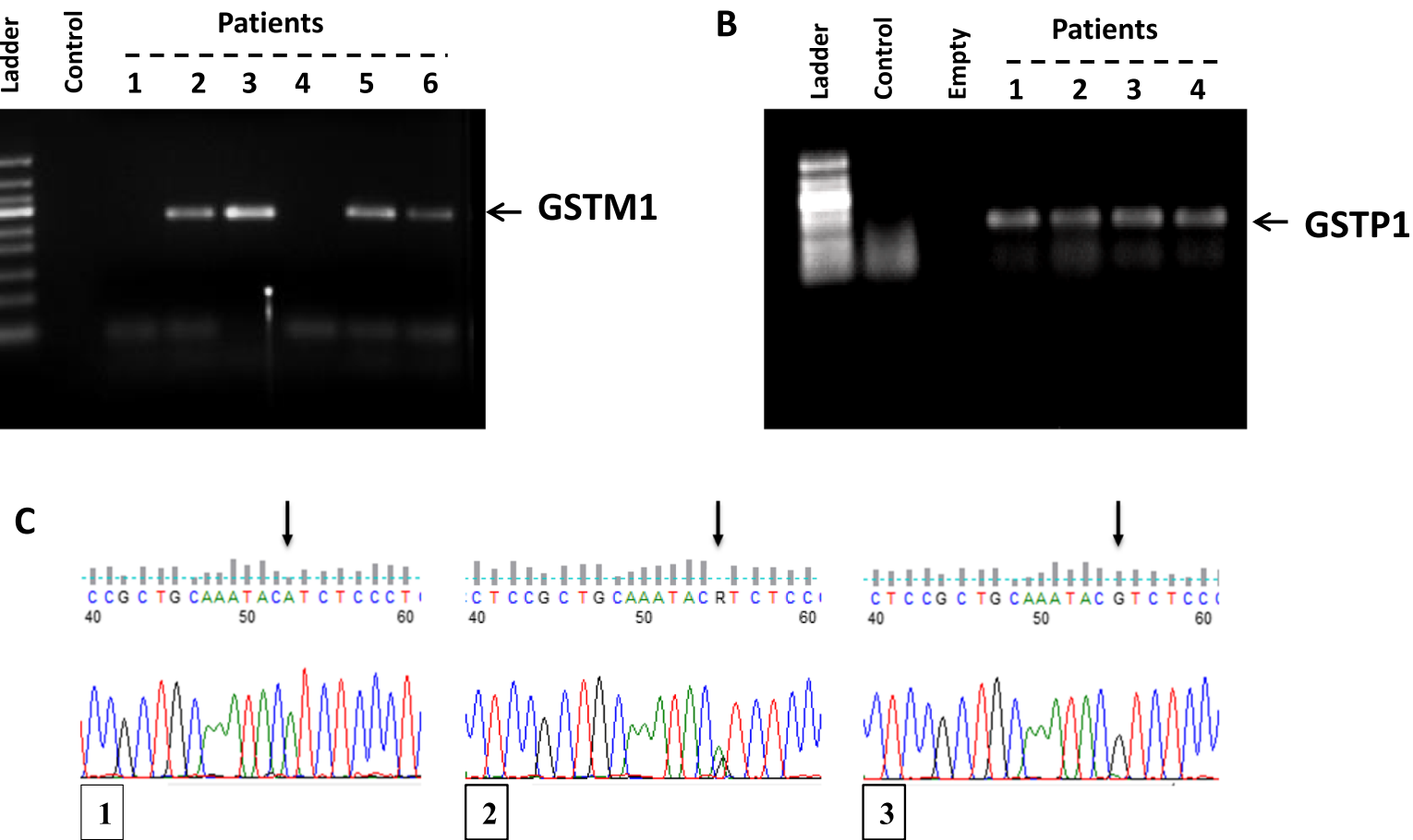

Fig. 1 Representative screening for GSTM1 and GSTP1 Polymerase chain reaction products. Agarose gel of the PCR products for detection of GSTM1 deletion polymorphism [a] GSTM1 verified by PCR analysis. b Agarose gel of the PCR products for detection of GSTP1 polymorphisms. c GSTP1 validation by sequencing: (1) The wild allele homozygote AA, (2) heterozygote AG and (3) variant allele homozygote GG genotypes

rank comparison test. Multiple logistic regression analysis was performed to assess the association between GST polymorphisms with aggressiveness of bladder cancer. Odds Ratios (OR) and their 95\% Confidence Intervals (95\% CI) were used to calculate the results. The wild type of all genotypes was used as the reference group. Interactions between GSTM1 and GSTP1 polymorphisms and aggressiveness bladder cancer phenotypes were analyzed using Spearman correlation analysis. In all tests, the values $p \leq 0.05$ were considered as statistically significant.

\section{Results}

\section{Characteristics of the study population}

In the current study, 93 patients with urinary bladder carcinoma were genotyped for two polymorphisms in two important genes of the glutathione-s-transferase family involved in xenobiotic metabolism. The distribution of the clinicopathological characteristics of the bladder cancer patients is presented in Table 1. Patients age ranges from 34 to 93 years with median age of $64 \pm 12$, the median follow-up time of 10.10 months (ranging $0-139$ months) and preponderance of male over female in the ratio 5:1.

\section{Genotype distributions of the GSTM1and GSTP1 polymorphisms in patients}

Polymerase chain reaction-based and Sanger gene sequencing-base assays were undertaken to assess the contribution of genetic polymorphism in GSTM1 and GSTP1 to the susceptibility of bladder cancer (Fig. 1). Lack of amplification products for the GSTM1 gene was considered as a homozygous null genotype $(-/-)$. Our data revealed that a total of 44 bladder cancer patients out of $93(47.31 \%)$ had a GSTM1-deleted genotype (-/-). GSTM1 specific bands showing on agarose gel electrophoresis was seen in 45 out of 93 patients $(48.38 \%)$. No further investigations were carried out to discriminate between heterozygous deletion $(+/-)$ and wild-type $(+/+)$ GSTM1 variants hence both heterozygous deletion and wild-type variants are considered GSTM1 present (Fig. 1a).

As for the GSTP1 frequencies, amplified PCR products containing GSTP1 were visualized on agarose gels (Fig. 1b) and the resultant DNA fragments were subjected to Sanger sequencing using BigDye terminator v3.1 (Life technologies). The GSTP1 wild allele homozygote (AA), heterozygote (AG) and variant allele homozygote (GG) genotypes were 36/93 (38.70\%), 36/93 (38.70\%) and 6/93 (6.45\%) respectively (Fig. 1c). Merging both AG/GG genetic variants represent 45.16\% (42/93) of the total analyzed cases, Table 2.

A higher frequency within our cohort was found between those carrying GSTM1 null and GSTP1 recessive homozygote / heterozygote AG/GG 23 (24.73\%), whereas the lower percentage was with GSTM1 null and the GSTP1 wild allele 14 (15.05\%) shown in Fig. 2. 
Table 2 The distribution (count and percentage) of GSTM1 and GSTP1 genotypes in the patients with bladder cancer

\begin{tabular}{llll}
\hline & & N & $\%$ \\
\hline GSTM1 & Present & 45 & $(48.38)$ \\
& Null & 44 & $(47.31)$ \\
GSTP1 & AA & 36 & $(38.70)$ \\
& GG & 6 & $(6.45)$ \\
& AG & 36 & $(38.70)$ \\
& AG/GG & 42 & $(45.16)$ \\
\hline
\end{tabular}

No statistical significant was found between GSTs different groups.

\section{Effect of GSTM1and GSTP1 polymorphisms on patients' survival}

Kaplan-Meier curve showed that GSTM1 null genotype was associated with poor overall survival in comparison to GSTM1 present genotype, $\log$ rank $p=$ 0.038 (Fig. 3a). As for GSTP1, though it is not statistically significant, patients harboring the wild type allele GSTP1 AA have tendency for better survival in comparison to patients with GSTP1 AG/GG genotype (Log rank, $p=0.234)$. GSTP1 AG carriers had the worst overall survival compared to GSTP1 AA or GG genotypes carriers (Fig. 3b, c. However, the associations were not statistically significant (log-rank test; $p=$ 0.40). When merging GSTM1 survival and GSTP1 polymorphisms (Fig. 3d), there was trend towards

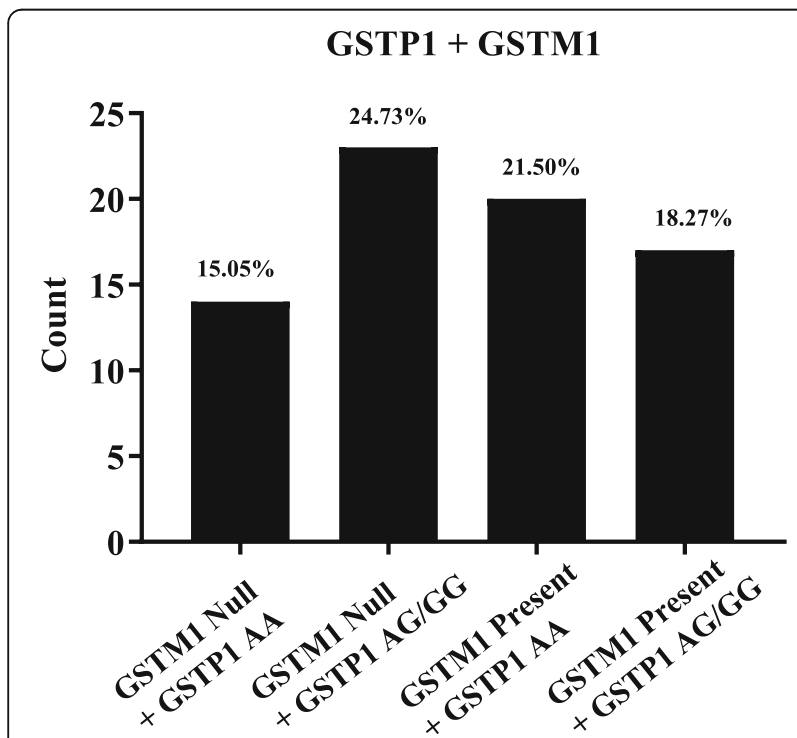

Fig. 2 Distribution of the GSTM1 + GSTP1 variants in bladder cancer patients. The distribution of patients carrying GSTM1 null and GSTP1 recessive homozygote/ heterozygote AG/GG was 23 of 93 (24.73\%). whereas the lowest was GSTM1 null and the GSTP1 wild allele $14(15.05 \%)$ poorer survival for patients with combined GSTM1 null and GSTP1 AG/GG (Log rank, $p=0.146$ ).

\section{Relationships between GST genotypes, HER2 status and survival outcomes}

Published data, including our own, revealed that bladder cancer exhibit high ratios of the Human Epidermal growth factor Receptor 2 (HER2) gene amplification, after breast and gastric cancers, and also demonstrates frequent overexpression of HER2 protein [33, 34]. Recently published data revealed that bladder cancer possess the highest frequency mutation in HER2 gene across 38 types of tumors analyzed [31]. Furthermore, HER2 is considered among the prognostic factors, along with staging and grading system, in urothelial bladder cancer [36]. In the current study we sought to investigate the relationship between GSTM1 and GSTP1 polymorphisms in respect to HER2 status of the same cohort. HER2 protein expression and gene amplification data [33] were available for 89 patients out of our 93 bladder cancer patients. Histograms showed the frequency of expression patterns of HER2 protein receptors in our cohort (Additional file 1: Figure S1). To establish the relationship between GST genotypes and HER2 status, bright field double in situ hybridization (BDISH) and immunohistochemistry (IHC) data were used to analyze HER2 gene amplification and protein expression within the GSTP1/ GSTM1 analyzed cohort. Our data indicated no association between HER2 protein level and both $\operatorname{GSTP1}(p=0.07)$ and GSTM1 $(p=0.75)$ polymorphic status (Table 3). However, HER2 gene amplification was significantly associated with the GSTP1 AA, AG \& GG variants $(p=0.03)$. Such a relationship was not established for amplified HER2 gene and GSTM1 null/present variants (Table 3).

Interestingly, Kaplan-Meier survival curve for GSTM1 status adjusted to HER2 gene status (amplified or nonamplified) showed a significant impact on patients' overall survival. Figure 4a, illustrates that poor overall survival was associated with combining GSTM1 null and amplified HER2 gene (Log rank, $p=0.05)$, though this was not the case with non-amplified HER2 patients (Fig. 4b). To further confirm the observed relationship between amplified HER2 gene and GSTM1 null, we sought to analyze the relationship between HER2 protein level and GSTM1 genotype. Similarly, survival curve (Fig. 4c) showed poor survival for patients carrying GSTM1 null variant with high HER2 protein expression (Log rank, $p=0.041$ ) compared to GSTM1 null/ low HER2 protein expression counterpart (Fig. 4D). This synergistic effect of combined GSTM1 genotype and increased HER2 status indicated a possible interaction between the two genes in bladder carcinogenesis. On the other hand, no difference in overall survival was observed in patients harboring combined 


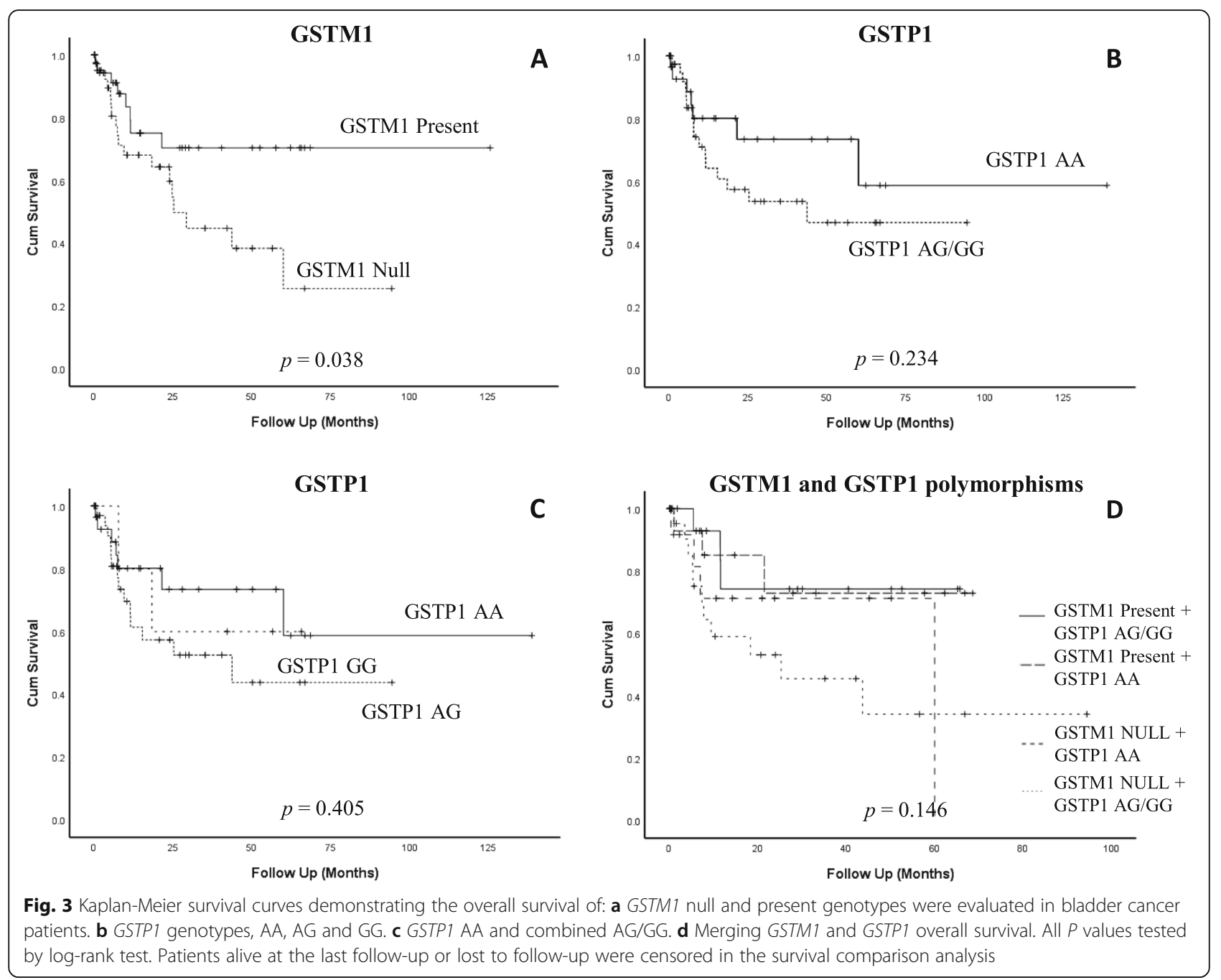

GSTP1 polymorphism and altered HER2 gene/protein levels (Additional file 2: Fig. S2A - 2D). The study cohort was then stratified into two groups based on the type of tumour (MIBC and NMIBC) and statistical analysis was performed to to determine which variables were independently associated with the patients' outcome. In a multivariate analysis polymorphic GSTs gene expression has no independent prognostic value on bladder cancer overall survival. Similarly, No independent prognostic value of HER2 status was observed on overall survival (Table 4).

Table 3 Interaction between GSTM1 and GSTP1 polymorphisms and HER2 status

\begin{tabular}{lccc}
\hline & GSTM1 & $\begin{array}{l}\text { GSTP1 } \\
\text { (AA, AG \& GG) } \\
\end{array}$ & $\begin{array}{l}\text { GSTP1 } \\
\text { (AA \& } \text { value } A G / G G) \\
P \text { value }\end{array}$ \\
\hline HER2 Gene & 0.42 & 0.03 & 0.08 \\
HER2 Protein & 0.75 & 0.11 & 0.07 \\
\hline
\end{tabular}

Considering the small number of patients in each group ( $M I B C=52$, NMIBC $=28$ ), it is meaningful to further explore its prognostic value in a large population size.

\section{GSTM1 and GSTP1 polymorphisms and clinicopathological parameters}

Multiple logistic regression analysis was performed to assess the association between GSTs polymorphisms with patients' clinical characteristics including tumor grade/ stage, muscle invasion, lymph node invasion, vascular invasion and metastasis. No association was observed between GSTM1 polymorphism and patients' clinicopathological characteristics. Similarly, no correlation was reported between GSTP1 gene variants and patients' clinicopathological features (Table 5).

\section{Discussion}

Globally, bladder cancer is a leading cause of mortality $[37,38]$. It has long been perceived that bladder cancer is a result of occupational and environmental exposure 


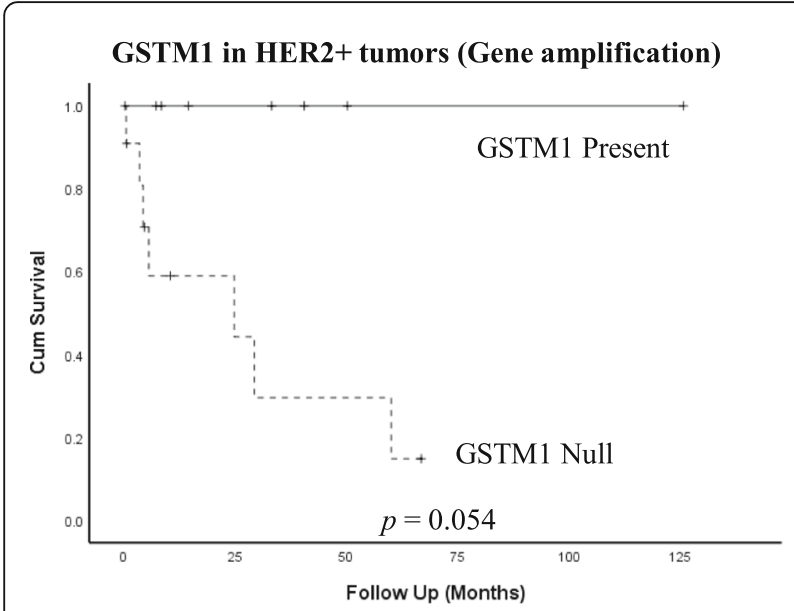

A

GSTM1 in HER2- tumors (Gene Non-amplification)
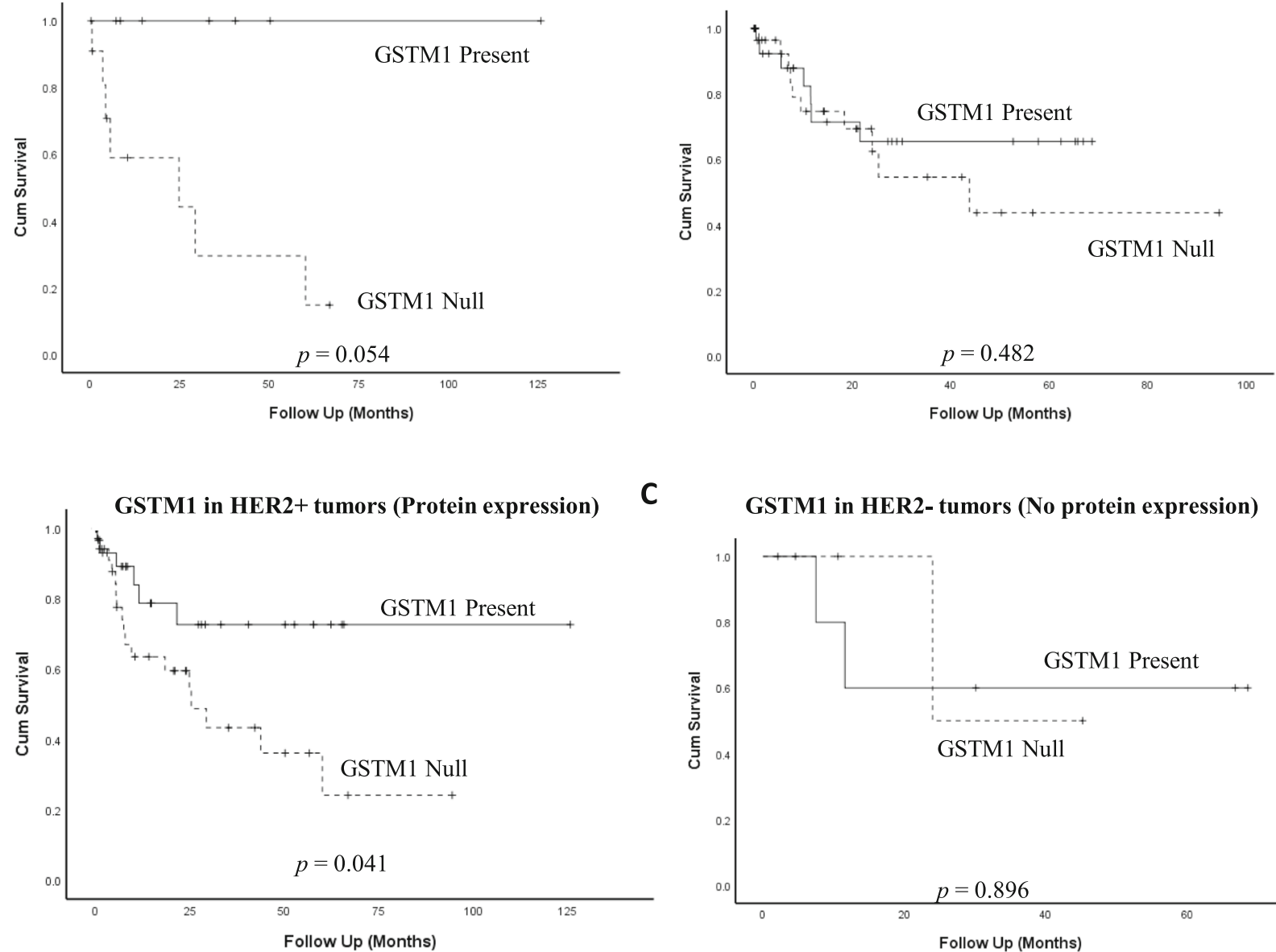

C

GSTM1 in HER2- tumors (No protein expression)

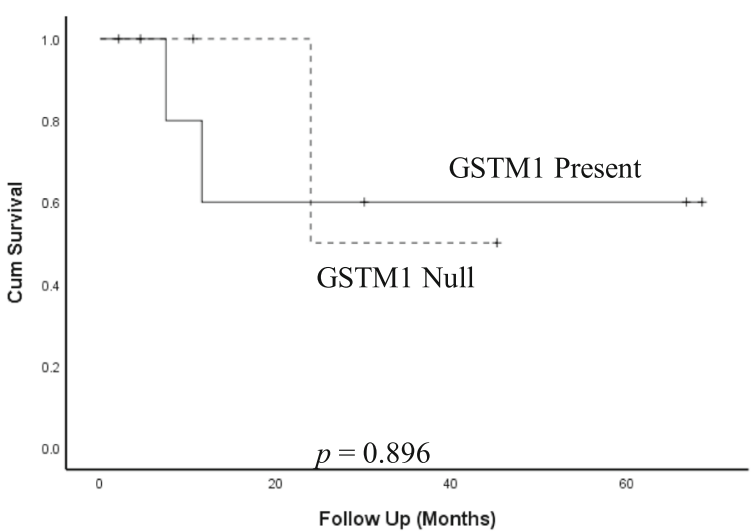

Fig. 4 Kaplan-Meier survival curves demonstrating the overall survival of GSTM1 adjusted with HER2 status. a GSTM1 genotypes with HER2 gene amplification. b GSTM1 genotypes with HER2 gene Non-amplification. c GSTM1 genotypes with HER2 Protein expression. d GSTM1 genotypes with No HER2 Protein expression

to carcinogens and tobacco smoking, however, the exact mechanisms of bladder carcinogenesis remain unclear. Recent findings suggested that genetic factors contribute potentially, through mutations in key genes, in the etiology and pathogenesis of bladder cancer [7, 8, 39]. Glutathione S-Transferases (GSTs) are members of a large gene family of cytosolic phase II xenobiotic metabolizing enzymes involved in catalyzing and detoxifying a variety of carcinogens including reactive electrophilic compounds [11]. Members of the GST family play an important role in cellular defense through conjugation of xenobiotics with sulfhydryl group and promoting their excretion at later stage $[11,40]$. It has been proposed that polymorphisms in members of GST of carcinogendetoxifying gene family as well as in NAT2 confer increased risk of bladder cancer [39]. Moreover, increased expression of GST family members, especially GSTP1 and GSTM1, was reported in several human solid tumors and is believed to confer resistance to various platinum- base chemotherapy drugs and metformin through regulation of many genes and molecular pathways [41, 42]. Mechanistically, it is believed that polymorphisms in genes involved in drug-metabolizing enzymes may result in drastic changes in carcinogens biotransformation leading to increased cancer susceptibility [2].

In our investigation we examined the frequency of GSTP1 and GSTM1 variants in a cohort of 93 bladder cancer patient from Saudi Arabia. We also evaluated the association between GSTP1 and GSTM1 gene polymorphisms with a set of clinical and pathological parameters as well as the prognostic value of both genes polymorphisms in bladder cancer patients.

The frequency and distribution of GSTM1 and GSTP1 gene variants was represented in Table 2. In our study, the ratio of GSTM1 present and null is equally distributed in our cohort 48.38 and $47.31 \%$ respectively. This data is in agreement with previous report on the frequency of the GSTM1 null genotype in the Caucasian 
Table 4 Multivariate analyses compared with patients' clinicopathological parameters, GSTs and HER2 status for bladder cancer overall survival

\begin{tabular}{|c|c|c|c|c|c|c|c|c|}
\hline \multirow[t]{3}{*}{ Variable } & \multicolumn{4}{|l|}{ NMIBC } & \multicolumn{4}{|l|}{ MIBC } \\
\hline & \multirow{2}{*}{$\begin{array}{l}\text { Hazard } \\
\text { ratio }\end{array}$} & \multicolumn{3}{|c|}{ 95\% Confidence Interval } & \multirow{2}{*}{$\begin{array}{l}\text { Hazard } \\
\text { ratio }\end{array}$} & \multicolumn{3}{|c|}{ 95\% Confidence Interval } \\
\hline & & Lower bound & Upper bound & $P$ value & & Lower bound & Upper bound & $P$ value \\
\hline Group age ( $\leq 60 />60$ Years) & 0.81 & -0.144 & 0.564 & 0.215 & 1.64 & -0.035 & 0.480 & 0.087 \\
\hline Gender (F/M) & 2.77 & -0.519 & 0.206 & 0.356 & 1.45 & -0.137 & 0.398 & 0.319 \\
\hline Tumor grade (High/Low) & 0.46 & -0.558 & 0.167 & 0.255 & 0.52 & -0.433 & 0.113 & 0.232 \\
\hline Tumor subtypes (Transitional/Squamous) & 1.75 & -0.383 & 0.363 & 0.953 & 1.41 & -0.173 & 0.367 & 0.459 \\
\hline Tumor shape (nonpapillary/papillary) & 1.48 & -0.099 & 0.594 & 0.142 & 1.07 & -0.207 & 0.335 & 0.626 \\
\hline Lymph node (present/absent) & 1.88 & -0.655 & 0.015 & 0.059 & 0.98 & -0.581 & -0.093 & 0.009 \\
\hline Vascular invasion (present/absent) & - & - & - & - & 0.66 & -0.496 & 0.026 & 0.075 \\
\hline Metastasis (present/absent) & 0.36 & -0.530 & 0.205 & 0.345 & 1.72 & -0.496 & 0.033 & 0.083 \\
\hline Smoking (yes/no) & 1.41 & -0.914 & 0.839 & 0.788 & 0.94 & -0.638 & 0.284 & 0.380 \\
\hline Family history of cancer (yes/no) & - & - & - & - & 0.38 & -0.578 & 0.338 & 0.546 \\
\hline GSTM1 status (present/null) & 1.21 & -0.400 & 0.374 & 0.940 & 0.95 & -0.510 & 0.002 & 0.052 \\
\hline GSTP1 status (AA/AG + GG) & 0.55 & -0.422 & 0.350 & 0.837 & 0.71 & -0.035 & 0.549 & 0.081 \\
\hline HER2 gene status (non-amplified/amplified) & 2.38 & -0.457 & 0.297 & 0.642 & 0.54 & -0.214 & 0.345 & 0.627 \\
\hline HER2 protein status (no expression/expression) & 2.14 & -0.459 & 0.310 & 0.669 & 1.04 & -0.151 & 0.390 & 0.366 \\
\hline
\end{tabular}

Table 5 Association between GSTM1 and GSTP1 polymorphisms and clinicopathological features

\begin{tabular}{|c|c|c|c|c|c|c|c|c|c|c|c|}
\hline & & \multicolumn{4}{|c|}{ GSTM1 } & \multirow[b]{3}{*}{$P$ value } & \multicolumn{4}{|c|}{ GSTP1 } & \multirow[b]{3}{*}{$P$ value } \\
\hline & & \multicolumn{2}{|c|}{ Null } & \multicolumn{2}{|c|}{ Present } & & \multicolumn{2}{|l|}{ AA } & \multicolumn{2}{|c|}{$\mathrm{AG} / \mathrm{GG}$} & \\
\hline & & $\mathrm{N}$ & $\%$ & $\mathrm{~N}$ & $\%$ & & $\mathrm{~N}$ & $\%$ & $\mathrm{~N}$ & $\%$ & \\
\hline \multirow[t]{2}{*}{ Group age (Years) } & $\leq 60$ & 17 & $18.2 \%$ & 20 & $21.5 \%$ & 0.51 & 16 & $17.2 \%$ & 16 & $17.2 \%$ & 0.49 \\
\hline & $>60$ & 27 & $29.0 \%$ & 24 & $25.8 \%$ & & 19 & $20.4 \%$ & 26 & $27.9 \%$ & \\
\hline \multirow[t]{2}{*}{ Gender } & Male & 37 & $39.7 \%$ & 37 & $39.7 \%$ & 0.81 & 32 & $34.4 \%$ & 33 & $35.4 \%$ & 0.22 \\
\hline & Female & 7 & $7.5 \%$ & 8 & $8.6 \%$ & & 4 & $4.3 \%$ & 9 & $9.6 \%$ & \\
\hline \multirow[t]{2}{*}{ Race } & Asian & 35 & $37.6 \%$ & 40 & $43.0 \%$ & 0.32 & 31 & $33.3 \%$ & 38 & $40.8 \%$ & 0.54 \\
\hline & African & 8 & $8.6 \%$ & 5 & $5.3 \%$ & & 5 & $5.3 \%$ & 4 & $4.3 \%$ & \\
\hline \multirow[t]{2}{*}{ Tumor Grade } & High Grade & 29 & $31.1 \%$ & 26 & $27.9 \%$ & 0.18 & 23 & $24.7 \%$ & 26 & $27.9 \%$ & 0.67 \\
\hline & Low Grade & 10 & $10.7 \%$ & 17 & $18.2 \%$ & & 12 & $12.9 \%$ & 11 & $11.8 \%$ & \\
\hline \multirow[t]{2}{*}{ Cancer Type } & MIBC & 28 & $30.1 \%$ & 23 & $24.7 \%$ & 0.17 & 18 & $19.3 \%$ & 21 & $22.5 \%$ & 1.00 \\
\hline & NMIBC & 10 & $10.7 \%$ & 16 & $17.2 \%$ & & 12 & $12.9 \%$ & 14 & $15.0 \%$ & \\
\hline \multirow[t]{3}{*}{ Subtypes } & Transitional & 32 & $34.4 \%$ & 39 & $41.9 \%$ & 0.08 & 30 & $32.2 \%$ & 35 & $37.6 \%$ & 0.23 \\
\hline & Squamous & 3 & $3.2 \%$ & 0 & $0.0 \%$ & & 0 & $0.0 \%$ & 3 & $3.2 \%$ & \\
\hline & Transitional/ Squamous & 9 & $9.6 \%$ & 5 & $5.3 \%$ & & 5 & $5.3 \%$ & 4 & $4.3 \%$ & \\
\hline \multirow[t]{2}{*}{ Lymph Node } & Positive & 13 & $13.9 \%$ & 7 & $7.5 \%$ & 0.14 & 8 & $8.6 \%$ & 10 & $10.7 \%$ & 0.93 \\
\hline & Negative & 30 & $32.2 \%$ & 35 & $37.6 \%$ & & 26 & $27.9 \%$ & 31 & $33.3 \%$ & \\
\hline \multirow[t]{2}{*}{ Vascular Invasion } & Positive & 10 & $10.7 \%$ & 7 & $7.5 \%$ & 0.41 & 6 & $6.4 \%$ & 9 & $9.6 \%$ & 0.60 \\
\hline & Negative & 32 & $34.4 \%$ & 35 & $37.6 \%$ & & 28 & $30.1 \%$ & 31 & $33.3 \%$ & \\
\hline \multirow[t]{2}{*}{ Metastasis } & Positive & 11 & $11.8 \%$ & 9 & $9.6 \%$ & 0.60 & 7 & $7.5 \%$ & 13 & $13.9 \%$ & 0.27 \\
\hline & Negative & 31 & $33.3 \%$ & 33 & $35.4 \%$ & & 27 & $29.0 \%$ & 28 & $30.1 \%$ & \\
\hline \multirow[t]{2}{*}{ Survival } & Alive & 26 & $27.9 \%$ & 37 & $39.7 \%$ & $0.01^{*}$ & 29 & $31.1 \%$ & 26 & $27.9 \%$ & 0.072 \\
\hline & Deceased & 18 & $19.3 \%$ & 8 & $8.6 \%$ & & 7 & $7.5 \%$ & 16 & $17.2 \%$ & \\
\hline
\end{tabular}


population [43]. In an independent study, Kang et al, revealed that the frequency of the GSTM1 null genotype was $59.1 \%$ in patients with muscle invasive bladder cancer (MIBC) [44]. Nonetheless, it is well documented that the prevalence of GSTM1 null genotype varies significantly among populations from different ethnic groups [45]. As for GSTP1 gene polymorphism when we considered patients holding at least one copy of the dominant allele, data indicated that the frequency of AA and AG genotypes were found to be significantly high in our study group with a combined ratio of $77.4 \%$ for both genotypes compared to the GG genotype (6.45\%). The reported frequency of GSTP1 AA/AG genotypes is around $67 \%$ of the Iranian patients [26] and Indian patients [46]. However, a slight high frequency, approximately $80 \%$, of GSTP1 AA/AG variants was observed in in the Caucasian population with bladder cancer [47].

We next sought to evaluate the association between polymorphism of the GSTP1 and GSTM1 genes and patients' outcome. Our results indicated a significant association between the null GSTM1 genotype and poor overall survival among bladder cancer patients. The association between GSTs and poor survival was previously highlighted in many cancer types including bladder cancer [48-50]. As for GSTP1 genotypes, our data show trend for better survival for patients with the wild allele homozygote AA in comparison to heterozygote AG and variant allele homozygote GG genotypes or to GG/AG combined though data are not significant. When GSTP1 GG/AG and GSTM1 null genotypes were present together, poor overall survival increased in comparison to GSTP1 alone.

The accumulating data suggested that genetic polymorphism of GSTs leads to reduced detoxification potential which may result in increased DNA adduct levels in the target tissues and eventual mutations in the driver genes leading carcinogenesis. Therefore, the association of GSTP1/ GSTM1 variants with highly malignant disease and poor prognosis in cancer patients was suggested [50].

Previous studies on patients from different ethnic origins revealed that individuals with the null GSTM1 were at high risk of developing bladder cancer [26, 51-54]. This association was also seen between GSTM1 null and other cancers such as breast [50], lung [55] and colorectal cancers [35]. Anwar et al. showed significantly higher GSTM1 null distribution in bladder cancer patients than in healthy individuals [51]. The distribution of the null GSTM1 in our cohort did not show any significant difference in comparison to the wild-type allele which may indicate that the null genotype is not the only factor in determining the increased risk and aggressiveness of bladder cancer but is certainly one of many combined genetic factors that contribute to the pathogenesis of the disease. To-Figueras et al. suggested a relation between GSTM1 null genotype and $p 53$ mutation in increasing the risk of lung cancer susceptibility among smokers [55]. In an early observation by Ryk et al. the investigators demonstrated that the carriers of the variant allele of the GSTP1 $\mathrm{Ile}_{105} \mathrm{Val}$ polymorphism were characterized by frequent mutations in the tumor suppressor gene p53 and high-grade/ high stage tumors in bladder cancer [56]. In an independent investigation we performed high throughput mutational analysis of 50 oncogenes and tumor suppressor genes using cancer hotspot panel (CHP, v.2). Our data indicated that high proportion ( $82 \%$ ) of our bladder cancer cohort harbor $p 53$ mutation (data not published) which may suggest the involvement of $p 53$ mutation in association with GSTP1 in the risk of bladder cancer development and drug resistance. This suggestion is valid knowing that GSTP1 gene contains a functional canonical p53 binding motif and the capacity of p53 to transcriptionally activate the human GSTP1 gene [57].

In the same context and for the first time we investigated the relationship between different GSTP1/GSTM1 variants and Human Epidermal growth factor Receptor 2 (HER2) gene/ protein status in bladder cancer patients. Our data indicated that patients with high HER2 protein expression/ gene amplification and null GSTM1 genotype had significant poor survival compared to patients with low HER2 expression and null GSTM1 genotype, suggesting that combining HER2 status with GSTM1 genotype may have a prognostic value for bladder cancer patients. The exact mechanism of the influence of GSTM1 and HER2 on bladder cancer is yet to be elucidated. Together, our data showed that GSTM1 gene deletion either alone or in combination with HER2 may serve as markers for bladder cancer prognosis.

We observed no association between the GSTP1 $\mathrm{Ile}_{105-}$ Val genotype, GSTM1 genotype alone or in combination with HER2 status and patients' clinicopathological features. This is consistent with previous published reports [29, 58], and disagree with Safarinejad et al [26] who found a significant increase in tumor grade and stage of bladder cancer patients carrying GSTP1 Val/Val genotype and GSTM1/GSTT1 double null genotypes.

\section{Conclusions}

The present study revealed that GSTM1 null genotype is significantly associated with poor overall survival in urinary bladder cancer patients. Furthermore, combined GSTM1 deletion and amplified HER2 gene might be considered as the worse prognostic genotype combination in bladder cancer. To the best of our knowledge, this is the first study to investigate the association between GSTs genes polymorphisms and HER2 status in Saudi bladder cancer patients. One of the limitations of the current 
investigation is scarcity of the sample size and clinical data used for correlation analysis. Therefore, further analyses using larger sample size are needed to investigate the functional significance of combined GSTM1 deletion and HER2 on bladder cancer prognosis. Furthermore, larger epidemiological studies are needed to assess the relationship between these genes and response to therapies (chemotherapy and anti-HER2 therapy) which may support their use as potential predictive biomarkers for bladder cancer treatment.

\section{Supplementary information}

Supplementary information accompanies this paper at https://doi.org/10. 1186/s12885-019-6244-6.

Additional file 1: Figure S1. Histograms showed the frequency of expression patterns of HER2 protein receptors in 93 of bladder cancer by $\mathrm{IHC}$

Additional file 2: Figure S2. Kaplan-Meier survival curves demonstrating the overall survival of GSTP1 adjusted with HER2 status. (A) GSTP1 genotypes with HER2 gene amplification. (B) GSTP1 genotypes with HER2 gene Non-amplification. (C) GSTP1 genotypes with HER2 Protein expression. (D) GSTP1 genotypes with No HER2 Protein expression.

\section{Abbreviations}

BDISH: Bright field double in situ hybridization; GSTM1: Glutathione S-

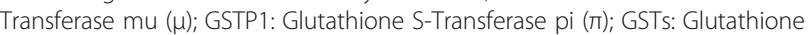
S-Transferases; HER2: Human epidermal growth factor receptor-2; IHC: Immunohistochemistry; TNM: Tumor, node and metastasis

\section{Acknowledgements}

The authors would like to acknowledge King Abdullah International Medical Research Center (KAIMRC) for their financial support to cover the publication fees. Data from this manuscript was presented as a poster presentation at the NCRI cancer conference 04-06 November 2018, Glasgow, United Kingdom (http://abstracts.ncri.org.uk/abstract/evaluation-of-the-prognostic-valueof-gstp1-and-gstm1-genetic-variants-in-urothelial-bladder-carcinoma/)

\section{Authors' contributions}

NA participated in revising the clinicopathological follow up data, data analysis and interpretation, designing images, tables and drafted the manuscript. DK performed the PCR and sequencing experiments. AD participated in study design and critically corrected the manuscript. J M collected patients' samples. TN designed the study, participated in retrieving and revising the clinicopathological follow up data, helped in data analysis and interpretation, and revising manuscript. All authors read and approved the final manuscript.

\section{Funding}

The authors would like to acknowledge King Abdullah International Medical Research Centre, Kingdom of Saudi Arabia, for the financial support (protocol number\# SF17/001/J). The funding body has no role in study design, data collection and analysis, interpretation of data; in the writing of the manuscript.

\section{Availability of data and materials}

The datasets used and/or analyzed during the current study are available from the corresponding author on reasonable request.

\section{Ethics approval and consent to participate}

The study was approved by the Ethics Committee of King Abdulaziz University Hospital, Jeddah, Saudi Arabia (Ref\#149-14). Written informed consents were taken from all participants in this study and both clinical and follow up data were retrieved according to the permission and guidelines of the Ethical Committee.
Consent for publication

Not applicable.

\section{Competing interests}

The authors declare that they have no competing interests.

\section{Author details}

'King Abdullah International Medical Research Center, King Saud bin Abdulaziz University for Health Sciences, Ministry of the National Guard Health Affairs, Jeddah, Kingdom of Saudi Arabia. ${ }^{2}$ King Fahd Medical Research Center, King Abdulaziz University, Jeddah, Saudi Arabia. ${ }^{3}$ Centre of Excellence in Genomic Medicine Research and Medical Laboratory Technology Department, Faculty of Applied Medical Sciences, King Abdulaziz University, Jeddah, Saudi Arabia. ${ }^{4}$ Department of Pathology King Abdulaziz University, Jeddah, Saudi Arabia. ${ }^{5}$ King Faisal Specialist Hospital \& Research Center, Jeddah, Saudi Arabia.

Received: 7 May 2019 Accepted: 7 October 2019

Published online: 23 October 2019

\section{References}

1. Bray F, Ferlay J, Soerjomataram I, Siegel RL, Torre LA, Jemal A. Global cancer statistics 2018: GLOBOCAN estimates of incidence and mortality worldwide for 36 cancers in 185 countries. CA Cancer J Clin. 2018:68(6):394-424.

2. Sanli O, Dobruch J, Knowles MA, Burger M, Alemozaffar M, Nielsen ME, et al. Bladder cancer. Nature Reviews Disease Primers. 2017:3:17022.

3. Youssef RF, Lotan Y. Predictors of outcome of non-muscle-invasive and muscle-invasive bladder cancer. TheScientificWorldJournal. 2011;11:369-81.

4. Boada LD, Henríquez-Hernández LA, Navarro P, Zumbado M, AlmeidaGonzález M, Camacho M, et al. Exposure to polycyclic aromatic hydrocarbons (PAHs) and bladder cancer: evaluation from a geneenvironment perspective in a hospital-based case-control study in the Canary Islands (Spain). Int J Occup Environ Health. 2015;21(1):23-30.

5. Kellen E, Zeegers M, Paulussen A, Vlietinck R, Vlem EV, Veulemans H, et al. Does occupational exposure to $\mathrm{PAHs}$, diesel and aromatic amines interact with smoking and metabolic genetic polymorphisms to increase the risk on bladder cancer?; the Belgian case control study on bladder cancer risk. Cancer Lett. 2007;245(1-2):51-60.

6. Ferrís J, Garcia J, Berbel O, Ortega JA. Constitutional and occupational risk factors associated with bladder cancer. Actas Urologicas Espanolas. 2013;37(8):513-22.

7. Brennan $\mathrm{P}$, Bogillot $\mathrm{O}$, Cordier $\mathrm{S}$, Greiser $\mathrm{E}$, Schill W, Vineis $\mathrm{P}$, et al. Cigarette smoking and bladder cancer in men: a pooled analysis of 11 case-control studies. Int J Cancer. 2000;86(2):289-94.

8. Saint-Jacques N, Brown P, Nauta L, Boxall J, Parker L, Dummer TJB. Estimating the risk of bladder and kidney cancer from exposure to low-levels of arsenic in drinking water, Nova Scotia, Canada. Environ Int. 2018;1 10:95-104.

9. Glaser AP, Fantini D, Shilatifard A, Schaeffer EM, Meeks JJ. The evolving genomic landscape of urothelial carcinoma. Nature Rev Urol. 2017:14:215.

10. Guengerich FP. Metabolism of chemical carcinogens. Carcinogenesis. 2000; 21(3):345-51.

11. Strange RC, Spiteri MA, Ramachandran S, Fryer AA. Glutathione-S-transferase family of enzymes. Mutat Res. 2001;482(1-2):21-6.

12. Mcllwain CC, Townsend DM, Tew KD. Glutathione S-transferase polymorphisms: cancer incidence and therapy. Oncogene. 2006;25(11):1639-48.

13. Sau A, Pellizzari Tregno F, Valentino F, Federici G, Caccuri AM. Glutathione transferases and development of new principles to overcome drug resistance. Arch Biochem Biophys. 2010;500(2):116-22.

14. Lin HJ, Han C-Y, Bernstein DA, Hsiao W, Lin BK, Hardy S. Ethnic distribution of the glutathione transferase mu 1-1 (GSTM1) null genotype in 1473 individuals and application to bladder cancer susceptibifity. Carcinogenesis. 1994:15(5):1077-81.

15. Benhamou S, Lee WJ, Alexandrie AK, Boffetta P, Bouchardy C, Butkiewicz D, et al. Meta- and pooled analyses of the effects of glutathione S-transferase M1 polymorphisms and smoking on lung cancer risk. Carcinogenesis. 2002;23(8):1343-50.

16. Ates NA, Tamer L, Ates C, Ercan B, Elipek T, Ocal K, et al. Glutathione S-transferase $\mathrm{M1}, \mathrm{T1}, \mathrm{P} 1$ genotypes and risk for development of colorectal cancer. Biochem Genet. 2005:43(3-4):149-63.

17. Singh M, Shah PP, Singh AP, Ruwali M, Mathur N, Pant MC, et al. Association of genetic polymorphisms in glutathione S-transferases and susceptibility to head and neck cancer. Mutat Res. 2008;638(1-2):184-94. 
18. Yin $\mathrm{X}$, Chen J. Is there any association between glutathione S-transferases M1 and glutathione S-transferases T1 Gene polymorphisms and endometria Cancer risk? A Meta-analysis. Int J Prev Med. 2017:8:47.

19. Agudo A, Sala N, Pera G, Capella G, Berenguer A, Garcia N, et al. No association between polymorphisms in CYP2E1, GSTM1, NAT1, NAT2 and the risk of gastric adenocarcinoma in the European prospective investigation into cancer and nutrition. Cancer Epidemiol Biomarkers Prev. 2006;15(5):1043-5.

20. Gorukmez O, Yakut T, Gorukmez O, Sag SO, Topak A, Sahinturk S, et al. Glutathione S-transferase T1, M1 and P1 genetic polymorphisms and susceptibility to colorectal Cancer in Turkey. Asian Pac J Cancer Prev. 2016;17(8):3855-9.

21. Piao JM, Shin MH, Kweon SS, Kim HN, Choi JS, Bae WK, et al. Glutathione-S-transferase (GSTM1, GSTT1) and the risk of gastrointestinal cancer in a Korean population. World J Gastroenterol. 2009;15(45):5716-21.

22. Saint-Ruf C, Malfoy B, Scholl S, Zafrani B, Dutrillaux B. GST pi gene is frequently coamplified with INT2 and HSTF1 proto-oncogenes in human breast cancers. Oncogene. 1991;6(3):403-6.

23. Ali-Osman F, Akande O, Antoun G, Mao JX, Buolamwini J. Molecular cloning, characterization, and expression in Escherichia coli of full-length cDNAs of three human glutathione S-transferase pi gene variants. Evidence for differential catalytic activity of the encoded proteins. J Biol Chem. 1997; 272(15):10004-12.

24. Tew KD, Manevich Y, Grek C, Xiong Y, Uys J, Townsend DM. The role of glutathione S-transferase $P$ in signaling pathways and S-glutathionylation in Cancer. Free Radic Biol Med. 2011;51(2):299-313.

25. Zhang Y, Yuan Y, Chen Y, Wang Z, Li F, Zhao Q. Association between GSTP1 lle105Val polymorphism and urinary system cancer risk: evidence from 51 studies. Onco Targets Ther. 2016;9:3565-9.

26. Safarinejad MR, Safarinejad S, Shafiei N, Safarinejad S. Association of genetic polymorphism of glutathione S-transferase (GSTM1, GSTT1, GSTP1) with bladder cancer susceptibility. Urol Oncol. 2013;31(7):1193-203.

27. Kellen E, Hemelt M, Broberg K, Golka K, Kristensen VN, Hung RJ, et al. Pooled analysis and meta-analysis of the glutathione S-transferase P1 lle 105Val polymorphism and bladder cancer: a HuGE-GSEC review. Am J Epidemiol. 2007;165(11):1221-30.

28. Fontana L, Delort L, Joumard L, Rabiau N, Bosviel R, Satih S, et al. Genetic polymorphisms in CYP1A1, CYP1B1, COMT, GSTP1 and NAT2 genes and association with bladder cancer risk in a French cohort. Anticancer Res. 2009;29(5):1631-5

29. Yu Y, Li X, Liang C, Tang J, Qin Z, Wang C, et al. The relationship between GSTA1, GSTM1, GSTP1, and GSTT1 genetic polymorphisms and bladder cancer susceptibility: a meta-analysis. Medicine. 2016;95(37):e4900.

30. Matic M, Pekmezovic T, Djukic T, Mimic-Oka J, Dragicevic D, Krivic B, et al. GSTA1, GSTM1, GSTP1, and GSTT1 polymorphisms and susceptibility to smoking-related bladder cancer: a case-control study. Urol Oncol. 2013:31(7):1184-92.

31. Meric-Bernstam F, Johnson AM, Dumbrava EEl, Raghav K, Balaji K, Bhatt M, et al. Advances in HER2-targeted therapy: novel agents and opportunities beyond breast and gastric Cancer. Clin Cancer Res. 2019;25(7):2033-41.

32. Tan TZ, Rouanne M, Tan KT, Huang RY, Thiery JP. Molecular subtypes of Urothelial bladder Cancer: results from a Meta-cohort analysis of 2411 tumors. Eur Urol. 2019;75(3):423-32.

33. Nedjadi T, Al-Maghrabi J, Assidi M, Dallol A, Al-Kattabi H, Chaudhary A, et al. Prognostic value of HER2 status in bladder transitional cell carcinoma revealed by both IHC and BDISH techniques. BMC Cancer. 2016;16:653.

34. Akbani R, Ng PK, Werner HM, Shahmoradgoli M, Zhang F, Ju Z, et al. A pan-cancer proteomic perspective on the Cancer genome atlas. Nat Commun. 2014;5:3887.

35. Khabaz MN, Nedjadi T, Gari MA, Al-Maghrabi JA, Atta HM, Bakarman M, et al. GSTM1 gene polymorphism and the risk of colorectal cancer in a Saudi Arabian population. Genet Mol Res. 2016;15(1). https://doi.org/10.4238/gmr.15017551.

36. Zhao J, Xu W, Zhang Z, Song R, Zeng S, Sun Y, et al. Prognostic role of HER2 expression in bladder cancer: a systematic review and meta-analysis. Int Urol Nephrol. 2015:47(1):87-94.

37. Antoni S, Ferlay J, Soerjomataram I, Znaor A, Jemal A, Bray F. Bladder Cancer incidence and mortality: a global overview and recent trends. Eur Urol. 2017;71(1):96-108

38. Felsenstein KM, Theodorescu D. Precision medicine for urothelial bladder cancer: update on tumour genomics and immunotherapy. Nat Rev Urol. 2018;15(2):92-111.

39. Knowles MA, Hurst CD. Molecular biology of bladder cancer: new insights into pathogenesis and clinical diversity. Nat Rev Cancer. 2015;15(1):25-41.
40. Lang M, Pelkonen O. Metabolism of xenobiotics and chemical carcinogenesis. IARC Sci Publ. 1999;148:13-22.

41. Sawers L, Ferguson MJ, Ihrig BR, Young HC, Chakravarty P, Wolf CR, et al. Glutathione S-transferase P1 (GSTP1) directly influences platinum drug chemosensitivity in ovarian tumour cell lines. Br J Cancer. 2014;111(6):1150-8.

42. Allocati N, Masulli M, Di llio C, Federici L. Glutathione transferases: substrates, inihibitors and pro-drugs in cancer and neurodegenerative diseases. Oncogenesis. 2018;7(1):8.

43. Carless MA, Lea RA, Curran JE, Appleyard B, Gaffney P, Green A, et al. The GSTM1 null genotype confers an increased risk for solar keratosis development in an Australian Caucasian population. J Invest Dermatol. 2002;119(6):1373-8.

44. Kang HW, Song PH, Ha YS, Kim WT, Kim YJ, Yun SJ, et al. Glutathione Stransferase M1 and T1 polymorphisms: susceptibility and outcomes in muscle invasive bladder cancer patients. Eur J Cancer (Oxford, England: 1990). 2013;49(14):3010-9.

45. Yu C, Hequn C, Longfei L, Long W, Zhi C, Feng Z, et al. GSTM1 and GSTT1 polymorphisms are associated with increased bladder cancer risk: evidence from updated meta-analysis. Oncotarget. 2017:8(2):3246-58.

46. Srivastava DS, Mishra DK, Mandhani A, Mittal B, Kumar A, Mittal RD. Association of genetic polymorphism of glutathione S-transferase M1, T1, P1 and susceptibility to bladder cancer. Eur Urol. 2005:48(2):339-44.

47. Harries LW, Stubbins MJ, Forman D, Howard GC, Wolf CR. Identification of genetic polymorphisms at the glutathione S-transferase pi locus and association with susceptibility to bladder, testicular and prostate cancer. Carcinogenesis. 1997;18(4):641-4.

48. Shiga $H$, Heath El, Rasmussen AA, Trock B, Johnston PG, Forastiere AA, et al. Prognostic value of p53, glutathione S-transferase pi, and thymidylate synthase for neoadjuvant cisplatin-based chemotherapy in head and neck cancer. Clin Cancer Res. 1999;5(12):4097-104.

49. Ruano-Ravina A, Garcia-Basteiro AL, Perez-Rios M, Gomez-Mosquera A Cerdeira-Carames S, Barros-Dios JM. Lung cancer survival and deletion of GSTM1 and GSTT1 genes. A case-series from Spain. Tumori. 2013;99(4):445-51.

50. Zhang J, Wu Y, Hu X, Wang B, Wang L, Zhang S, et al. GSTT1, GSTP1, and GSTM1 genetic variants are associated with survival in previously untreated metastatic breast cancer. Oncotarget. 2017;8(62):105905-14.

51. Anwar WA, Abdel-Rahman SZ, El-Zein RA, Mostafa HM, Au WW. Genetic polymorphism of GSTM1, CYP2E1 and CYP2D6 in Egyptian bladder cancer patients. Carcinogenesis. 1996;17(9):1923-9.

52. Katoh $T$, Inatomi $H$, Kim H, Yang M, Matsumoto $T$, Kawamoto T. Effects of glutathione S-transferase (GST) M1 and GSTT1 genotypes on urothelial cancer risk. Cancer Lett. 1998;132(1-2):147-52.

53. Srivastava DS, Kumar A, Mittal B, Mittal RD. Polymorphism of GSTM1 and GSTT1 genes in bladder cancer: a study from North India. Arch Toxicol. 2004;78(8):430-4.

54. Shao J, Gu M, Zhang Z, Xu Z, Hu Q, Qian L. Genetic variants of the cytochrome P450 and glutathione S-transferase associated with risk of bladder cancer in a south-eastern Chinese population. Int J Urol. 2008;15(3):216-21.

55. To-Figueras J, Gene M, Gomez-Catalan J, Galan C, Firvida J, Fuentes M, et al. Glutathione-S-Transferase M1 and codon 72 p53 polymorphisms in a northwestern Mediterranean population and their relation to lung cancer susceptibility. Cancer Epidemiol Biomarkers Prev. 1996;5(5):337-42.

56. Ryk C, Berggren $P$, Kumar $R$, Hemminki K, Larsson $P$, Steineck $G$, et al. Influence of GSTM1, GSTT1, GSTP1 and NAT2 genotypes on the p53 mutational spectrum in bladder tumours. Int J Cancer. 2005;113(5):761-8.

57. Lo HW, Stephenson L, Cao X, Milas M, Pollock R, Ali-Osman F. Identification and functional characterization of the human glutathione S-transferase P1 gene as a novel transcriptional target of the p53 tumor suppressor gene. Mol Cancer Res. 2008:6(5):843-50.

58. Grando JP, Kuasne H, Losi-Guembarovski R, Sant'ana Rodrigues I, Matsuda $H M$, Fuganti PE, et al. Association between polymorphisms in the biometabolism genes CYP1A1, GSTM1, GSTT1 and GSTP1 in bladder cancer. Clin Exp Med. 2009;9(1):21-8

\section{Publisher's Note}

Springer Nature remains neutral with regard to jurisdictional claims in published maps and institutional affiliations. 